\title{
The Logic of 'If-Then' Propositions 1
}

JOHN HOAGLUND

\section{Introduction}

In this paper, I am going to suggest an interpretation of 'if...then...' statements different from material implication which I hope is closer to our legitimate use of such statements in ordinary language. For most of us the paradoxes of material implication are old acquaintances:

If $2+2=5$, then ellipses are only circles that have lost their resilience.

Interpreted as a material implication, this statement is true. It has a false antecedent, and a material implication is always true when its antecedent is false.

If Oregon is an Asian nation, then

hickory makes good axe handles.

Similarly interpreted, this statement is true also. It has a true consequent, and a material implication is always true when its consequent is true.

Why is the interpretation of such statements as true paradoxical? The average person, confronted with such statements, is apt to say they're false, [1a] or that they don't make much sense. The paradox results when the logician replies that they're true. For him the content of the statement is not a matter of interest. The symbolic
Christopher Newport College

logician interprets 'if... then...' statements truth functionally, which means that the truth value of the material implication is determined solely by the truth or falsity of its antecedent and consequent considered separately. The truth or falsity of these simple statements may be determined by observation, by reports from others, by general knowledge or what have you, but not (usually) by logic. Such a material implication is false only when the antecedent is true and the consequent false. It is true for all other cases.

Since everyone concedes that the interpretation of 'if...then...' statements as material implications yields paradoxes, why is it adopted (at times with misgivings) in so many beginning logic textbooks? [2] Bertrand Russell seems more responsible than anyone else for the prominence of material implication in 20th century logic. The program of his Principles of Mathematics [3] is to construct the arithmetic of natural numbers in logical terms alone, or as some have put it, to reduce mathematics to logic. His strategy is to define natural numbers in terms of classes, then other numbers in terms of natural numbers. The 'if... then...' statement enters as a logical constant, too basic to be further defined 
(p. 14), and takes a central role in Russell's program. "Pure mathematics is the class of all propositions of the form ' $p$ implies $q$ ', where $p$ and $q$ are propositions containing one or more variables, the same in the two propositions, and neither $p$ nor $q$ contains any constants except logical constants" (p.4).

Russell then explains 'if... then...' statements or implications in terms we now call truth functional. "If $p$ implies $q$, then both are false or both are true; it is impossible to have $q$ false and $p$ true, and it is necessary to have $q$ true or $p$ false" (p. 15). Now comes his distinction of material from formal implication, which at times seeems evanescent to the present writer. [4] Formal implication is a relation of propositional functions: If ' $x$ is a man', then ' $x$ is mortal'. A propositional function becomes a proposition when you assign a value to the individual variable. In this case you can let $x=$ Socrates, with the result: If Socrates is man, then Socrates is mortal. Material implication is a relation of propositions: If $p$ then $q$, where it isn't possible for $p$ to be true and $q$ false. Letting $p=$ Socrates is a man, and $q=$ Socrates is mortal, your material implication is: If Socrates is a man, then Socrates is mortal.

So one reason why material implication is prominent is because of its role in Bertrand Russell's logic. It is the only 'if... then...' connector of propositions. Propositional functions as such are neither true nor false, so formal implication as holding for them has no direct bearing on statements that are true or false. Propositions and statements are either true or false (even when we don't know which), so material implication is the only 'if...then...' relation applicable to them. A logic of ordinary language deals primarily with statements that can be either true or false, so on Russell's view it appears that it must use material implication. G.E. Moore disputed the claim that material implication captured the relation of all 'if... then...' statements. [5]
But Russell's interest was less in a logic of ordinary language than in the system he devised with A.N. Whitehead in Principa Mathematica. [6] The advantage of interpreting 'if... then...' statements truth functionally was that it fit them in with surpassing neatness to the other materials of the system. Negation and disjunction are introduced first as primitive ideas, then material implication is defined in their terms:

$$
P \supset Q=-P v Q D f
$$

Other basic material is no less dependent on interpreting 'if...then...' statements truth functionally. Disjunctive addition, for instance, which is introduced as the second primitive proposition or axiom.

$$
\mathrm{Q} \supset(\mathrm{P \vee Q})
$$

When you substitute $-P$ for $P$, you generate all of the true consequent paradoxes of material implication.

$$
\begin{aligned}
& \mathrm{Q} \supset(-\mathrm{P} \vee \mathrm{Q}) \\
& \mathrm{Q} \supset(\mathrm{P} \supset \mathrm{Q})
\end{aligned}
$$

Among the other axioms, permutation and association seem better tailored to preserving associative and commutative properties of operations on numbers than preserving properties of 'if...then...' statements in ordinary language

An idea of the centrality of material implication in propositional logic as it is commonly taught can be gleaned from the following truth table.

$\begin{array}{cccccccc}P & Q & -P & -Q & -P v Q & P .-Q & -(P .-Q) & P \supset Q \\ t & t & f & f & t & f & t & t \\ t & f & f & t & f & t & f & f \\ f & t & t & f & t & f & t & t \\ f & f & t & t & t & f & t & t\end{array}$

If you relinquish material implication and the truth functional interpretation of 'if...then...' statements, then you must also relinquish either the final column or the two bottom lines of this truth table. Similar losses throughout would impoverish propositional logic. 
Another reason for the prominence of material implication is the great influence exerted by the logical system of the Principia on 20th century logic altogether. Material implication is the only 'if...then...' connector of propositions in the most influential logical system of the 20th century.

Russell appears not to have been much interested in working out the epistemological details of applying material implication to ordinary language. In developing from the Platonic realism of his Cambridge thesis[7] to the phenomenalism of his articles on logical atomism [8] his curiosity was exercised more in dispersing proper nouns into definite descriptions [9] and in devising a theory of types to resolve his and other class membership paradoxes.[10] But he did work through to a vision of a general position which would permit such details to be thrashed out. J.O. Urmson provides a very helpful sketch of this position.[11]

Russell...considered that a logic from which the whole of mathematics with all its complexities can be derived must be an adequate skeleton...of a language capable of expressing all that can be accurately said at all.

...he came to think that the world would have the structure of this logic, whose grammar was so perfect, unlike that of the misleading natural languages. As the logic had individual variables in its vocabulary so the world would contain a variety of particulars, the names of which would be constants to replace...these variables; as the logic required only extensional, truth-functional connectives between its elementary propositions, so the world would consist of independent, extensionally connected facts;... The structure of the world would thus resemble the structure of Pricipia Mathematica.

Wittgenstein appeared to bring us a step closer to realizing this in his Tractatus Logico-Philosophicus [12] with a position that Russell in his "Introduction" to this work generally approves. You express some observation in a logically simple atomic propo- sitions like 'The hat is red'. Then you combine this with a similar proposition by truth functional connective in a compound proposition like 'The hat is red and the purse is mauve'. When the simple propositions are true and the molecular proposition is interpreted truth functionally, it mirrors its corresponding reality. You don't make an observation that determines the truth value of a molecular proposition, then advance from this to the truth value of this constituent parts (though I believe we rightfully do this in the case of some 'if... then...' statements.)

So a third reason for the prominence of material implication was a conviction in the 1920s that a general position was within reach that would permit details of its application to be worked out.

But these far-reaching, programmatic aspirations were dampened by the proofs of Gödel in 1931 [13] that you cannot prove meta-mathematically the consistency of any system like the Principia's that founds the whole of arithmetic, and that such systems are essentially incomplete in that there are true arithmetical statements that cannot be derived from any given consistent set of arithmetical axioms. Also in the 1930s Wittgenstein came to seriously question his position in the Tractatus. He entertained doubts that the descriptive use of language in atomic propositions enjoyed logical priority over the many other uses of language, and arrived at the position he elaborated in his Philosophical Investigations. [14]

There were also determined efforts to work out a logic of 'if...then...' statements closer to their use in ordinary language. C.I. Lewis advanced in considerable detail an interpretation he called strict implication, which led to the development of modal logic.[15] More recently Anderson and Belnap put forward an intriguing 'relevance' interpretation that also breaks with material implication.[16] Unfortunately neither has much influenced the logic taught in the 
introductory logic course. If they had, my current endeavor - to link antecedent and consequent semantically in a way consonant with ordinary experience and usage-would be superfluous.

\section{Conditional Statements}

As an informal logician my interest is in the analysis and construction of inferences and arguments in ordinary language. We are specially interested in what merits inclusion in the first (often, alas, the only) course in practical reasoning, critical thinking, or informal logic taken by the college student. (My own teaching involves students of diverse backgrounds, interests, and levels of ability.) Gary Bedell has argued persuasively that material implication does not belong in such a course, [17] and I agree.

Should 'if...then...' statements be treated at all in such a course? To put it simply, they occur too frequently and play too prominent a role in our reasoning not to be included. Any time we are considering possibilities we are likely to be using some 'if...then...' statements. Modus ponens and related arguments are nearly always taught might have happened in the past, usually involves some such statements. When a scientist formulates a hypothesis to explain a phenomenon he is probably using some 'if...then...' statements. Modus ponens and related arguments are nearly always taught among common forms of argument, and they too employ 'if...then...' statements.

My thesis is that a considerable number of 'if...then...' statements are conditional statements (I don't know how many), and that conditional statements are established true or false differently from material implications. A conditional statement is true when its antecedent cites an actual condition of the event, state of affairs, or whatever is cited in the consequent. It is false when the antecedent does not cite such a condition. The evidence for the truth or falsity of a conditional statement is similar to the evidence that counts for one of Wittgenstein's atomic propositions: personal experience, reports of others, general knowledge.

Here is an example of a true conditional statement:

If you touch the tip of the sparkplug while the mower is on, you'll get a shock.

Here is an example of a false conditional statement:

If you put salt in lemonade, you'll make the cirink sweeter.

So interpreted, the conditional statement is not truth-functional. This distinguishes it from material implication. The conditional statement can only be true when antecedent and consequent are related in meaning. This stricture is contrary to truth functionality and does not apply to material implication. An example may illustrate:

If Dubuque is a city in lowa, then hydrogen peroxide is a good disinfectant for minor cuts and scratches.

Interepreted as a material implication, this statement is true because both antecedent and consequent are true. Interpreted as a conditional, it is false because the antecedent is unrelated in meaning to the consequent and does not give a condition of its state of affairs.

It may be objected at this point that since logic is concerned only with syntactic relations, I am leaving it (logic) behind in introducing this semantic factor. But one of the reason why we have an informal logic movement today is because we don't have a logical syntax that yields sound normative guidance for reasoning in ordinary language. My top priority is finding just this sound normative guidance, for the sake of which syntax and semantics will have to fall as they may.

So far I contend that some 'if... then...' statements are better interpreted as conditionals than as material 
implicatons. Futher help in understanding conditions may come from the widely accepted distinction of sufficient from necessary conditions. A sufficient condition is one whose satisfaction produces a desired or envisaged result:

If you turn the key, the door unlocks.

Here turning the key is a sufficient condition of unlocking the door. A necessary condition is one without whose satisfaction the result cannot be attained, but whose satisfaction does not guarantee the result:

If the car engine lasts the oil has been changed regularly.

Regular oil changes are a necessary condition of a lasting engine. Without them, the moving metal parts of the interior will wear more rapidly. But they are not a sufficient condition. Other periodic maintenance, such as changing plugs and points, must also be performed.

The provenance of this distinction is of interest. It appears not to have attracted the attention of our major historians of logic.[18] Perhaps the following remarks will spur some able investigator to pursue its history. It could well stem from J.S. Mill's examination of inductive reasoning in the System of Logic, especially the discussion of causation.[19] Mill distinguishes the comparatively rare case of a phenomenon with a single isolated cause (sufficient condition) from those events produced by the combined force of several antecedents (each perhaps a necessary condition).

Discussing Mill's methods and a plurality of causes in their Introduction to Logic and Scientific Method,[20] Cohen and Nagel distinguish sufficient conditions from those that are both necessary and sufficient. Then in Practical Logic,[21] Monroe Beardsley draws basically the same distinction as that 1 made earlier of necessary from sufficient conditions, in the hope of illuminating the concept 'cause'. Finally in Practical Reasoning in
Natural Language [22] Stephen N. Thomas provides a long and useful discussion of necessary and sufficient conditions. One merit of Thomas's account is that it is not restricted to interpreting Mill's methods. Another is the type of exercise he devises to encourage us to recognize and think about conditional relations. [23]

\section{Necessary and Sufficient Conditions}

How can this distinction now be brought to bear on the interpretation of conditional statements? Here is what I propose:

In a true conditional statement, the antecedent gives a sufficient condition of the consequent, and the consequent gives a necessary condition of the antecedent. In a false conditonal statement these relations do not hold.

Notice that to say what I want to say here I am cutting (probably giddily) through the Byzantine complexity of reference and using 'antecedent' to mean 'referent of the antecedent', etc. An example or two may help illustrate:

If you're in Nigeria, you're in Africa.

Being in Nigeria is a sufficient condition of being in Africa. But it isn't a necessary condition, since you can be in Chana or Algeria and still be in Africa. Being in Africa is a necessary condition of being in Nigeria, since you can't be in Nigeria without being in Africa. But it isn't a sufficient condition, since you could also be in Chana or Algeria.

If the car engine lasts, the oil has been changed regularly.

A lasting engine is a sufficient condition of regular oil changes, since the engine will only last when these changes have been made. But it isn't a necessary condition, since these changes can have been made without the engine lasting. [24] 
An interpretation of conditional statements would have a stronger claim on our attention if it proved helpful not only in analyzing conditional statements but also in understanding their use in logic. The present interpretation does go some distance in that direction. For instance, as conditional statements are commonly treated in logic, two operations of immediate inference are performed on them: conversion (which doesn't work) and contraposition (which does). Here is a conditional statement and its converse:

If she's a senator, then she's an American citizen.

If she's an American citizen, then she's a senator.

This true conditional statement does not convert, as the false derived statement shows. The reason why (in many or most cases) the converse of a true conditional statement is not true is that the consequent gives a necessary but not a sufficient condition of the antecedent. In the above, being an American citizen is a necessary condition of being a senator, but not a sufficient one. You must in addition win an election (or be appointed by due authority), take an oath of office, etc.

Our present interpretation also affords some help with those fewer cases where a conditional statement does convert:

If you're in Richmond, you're in the capital of Virginia.

If you're in the capital of Virginia, you're in Richmond.

Conversion works in this case because the consequent gives both necessary and sufficient conditions of the antecedent.

When we turn to contraposition, we find this interpretation helpful here too.

If the engine turns over, the battery is charged.

If the battery isn't charged, the engine doen't turn over.
The contrapositive of a true conditional statement is always true because in a true conditional statement the consequent gives a necessary condition of the antecedent. In our case, a charged battery is a necessary condition of the engine turning over.

Finally we may check its application to commonly taught conditional arguments and fallacies, beginning with modus ponens:

\section{If the viscous liquid in the pan is paint remover, then it seriously burns the skin on contact. \\ The viscous liquid is paint remover. \\ So the viscous liquid seriously burns the skin on contact.}

The reason why modus ponens with a true conditonal statement yields a true conclusion on this interpretation is that the antecedent gives a sufficient condition of the consequent. Here the liquid being paint remover is a sufficient condition of its seriously burning the skin on contact.

Another example illustrates its application to modus tollens:

\section{If the tree is a doogwood, it will produce white or pink flowers in the spring. \\ The tree doesn't produce such flowers in the spring.}

So the tree isn't a dog wood.

The reason why negating the consequent yields a negated antecedent as conclusion is because the consequent gives a necessary condition of the antecedent. In this case, producing white or pink flowers in spring is a necessary condition of being a dogwood. I believe we tend almost automatically to make adjustments for those cases where the tree is a dogwood but for one reason or another (disease, late frost) doesn't produce such flowers. Whether or not classroom time is well spent exploring such subtleties is a matter best left to the discretion of the individual teacher. He or she knows how much time there is to spend with the students, what their abilities and problems are, and what is most 
important for them to learn. My experience has been that lengthy discussion of such subtleties tends to bore students in introductory courses.

Our interpretation also helps illuminate the formal fallacy of denying the antecedent:

If it's playing at the Ritz, then it's a good movie.

It's not playing at the Ritz.

Thus it's not a good movie.

In a true conditional statement, the antecedent gives a sufficient but not a necessary condition of the consequent. This conditional statement says that any movie playing at the Ritz will be a good movie. But it doesn't state that any movie not playing at the Ritz will be a poor movie. Whether a movie not playing at the Ritz is good or poor is a question the conditional statement leaves open.

Our last example is a fallacy of affirming the consequent:

If it's genuine Harris tweed, then it's produced in the Hebrides.

It is tweed produced in the Hebrides.

So it must be genuine Harris tweed.

The reason why this argument is fallacious is that in a true conditional statement, the consequent gives a necessary but not a sufficient condition of the antecedent. Being produced in the Hebrides is a necessary condition for Harris tweed. But it is not a sufficient condition. For instance, the wool might be reclaimed rather than virgin, or produced by machine rather than hand woven.

\section{Material Implication Less Serviceable}

In summing up, let me stress the tentative and exploratory character of this interpretation of some 'if... then...' statements. No doubt it raises more questions than it answers. I offer it in the hope that it will be studied and criticized, and improved or rejected for a better interpretation. It in not necessary to challenge material implication in its logical domain in order to use the above interpretation to analyse and construct inferences in ordinary language. 'If...then' statements as here interpreted can easily be introduced in the system of the Principia. For instance, they can be introduced into the logic of relations, which Russell also pioneered, by letting them be a special case of Rab where $R=$ 'if...then...' as interpreted above. But this interpretation does offer decided advantages over material implication for the task of analysing arguments in ordinary language.

One reason why it is not more widely realized how poorly material implication functions as an interpreter of conditional arguments in ordinary language is the lack of a competing interpretation. This lack may now be remedied somewhat. Anderson and Belnap recognize [25] that no one constructs modus ponens on the paradoxically true 'if... thens...'

Common sense and interest automatically filter out the false antecedent variety. And there's little point building one on the true consequent variety, since the modus ponens only establishes superfluously what you already know, viz. that the consequent is true.

The basic conditional arguments advance from a true conditional statement to establish the truth or falsity of a constituent part. Yet on the truthfunction interpretation, you don't know that your conditional is true until you know the truth values of its parts, and when you know these your argument is superfluous. Russell, an inventor of truth functionality, may have been partially fielding this objection when he structured his modus ponens first antecedent, then conditionnal statement.[26] The above interpretation avoids this by allowing us to begin with a conditional statement whose truth is established by observation or general knowledge rather than by truth functionality.

In a way the choice is between confronting your beginning students with paradoxes that are never resolved or with what seems more like common 
sense. Somewhere in ironic commentary on the principle credo quia absurdum est, Francis Bacon says the more absurd a proposition of faith is, the more we honor God in accepting it.
While this may be good policy in dealing with the supernatural, it seems of quite dubious merit in a logic of argumentation.

\section{NOTES}

[1] Valuable comments by the editors of Informal Logi removed some serious mistakes from an earlier version of this article.

[2] E.g. Robert Fogelin, Understanding Arguments, 2nd ed. (New York, 1982), pp. 167-169; Gerald Runkle, Good Thinking (New York, 1981), pp. 90-92; Max Hocutt, The Elements of Logical Analysis and Inference (Cambridge, Mass., 1979), pp. 117-121; James D. Carney \& Richard K. Sheer, Fundamentals of Logic, 2nd ed. (New York, 1974) pp. 168-171.

[3] Cambridge University Press, 2nd edition, Allen \& Unwin, 1937.

[4] It is small consolation that quite able logicians like Alfred Tarski [Introduction to Logic, 3rd ed. (New York, 1965); pp. 23-28) and historians of logic like Anton Dumitriu [History of Logic, Vol. 4 (Turnbridge Wells, 1977), $p$. 90) also have difficulty with it. Today I believe we would say the propositional function contains free variables, the proposition no free ones (see Irving Copi, Symbolic Logic, 5th ed. (New York, 1979), p. 89f.). In A Hundred Years of Philosophy, 2nd ed. (London, 1966), John Passmore has treatment of this and related points in Russel which has proven very helpful (pp. 215-241).

[5] "External and Internal Relations," Philosophical Studies, (New York, 1922), pp. 276-309.

[6] Second ed., 3 vols. (London, 1927); 1978 reprint.
[7] The Foundations of Geometry (1987).

[8] "The Philosophy of Logical Atomism to July 1919," Monist, Vol. 28 (1918), pp. 495-527; Vol. 29 (1919), pp. 32-63, 190-222; 345380.

[9] "On Denoting," Mind, Vol. 14 (1905), pp. 479-493.

[10] "Mathematical Logic as Based on the Theory of Types," American Journal of Mathematics, Vol. 30 (1908), pp. 222-262.

[11] Philosophical Analysis (Oxford, 1965), p. 7; cf. G.J. Warnock, English Philosophy Since 1900 (London, 1958), p. 38f.

[12] London, 1960.

[13] See Ernest Nagel \& James R. Newman, Cödel's Proof (New York, 1958). Gödel's formidably technical "Ueber formale unesntscheidbare Sätze der Principia Mathematica und verwandter Systeme" appeared first in Monatshefte für Mathematik und Physik, Vol. 38 (1931), pp. 173198.

[14] Third ed. (New York, 1968).

[15] C.I. Lewis \& C.H. Langford, Symbolic Logic (New York, 1932).

[16] Entailment. The Logic of Relevance and Necessity (Princeton, 1975).

[17] "Teaching the Material Conditional," Teaching Philosophy, Vol. 2 (1979-80), esp. p. 233. 
[18] William Kneale and Martha Kneale, The Development of Logic (Oxford, 1962), I.M. Bochenski, History of Formal Logic (Notre Dame, 1961); for Dumitriu see note 4 above.

[19] This is Bk. III, Ch. 5 Ed. by E. Nagel as Philosophy of Scientific Method (New York, 1950), pp. 194-198.

[20] (New York, 1934) pp. 269-272.
[21] (New York, 1950), p. 464.

[22] Second ed. (Englewood Cliffs, 1981), pp. 129-169.

[23] Page 141.

[24] The consequent is interpreted on p. 8 above.

[25] Page 17f.

[26] In the Principia.

\section{APPENDIX}

[1a] In my elementary logic class at Christopher Newport College (which has now become a sixhour critical thinking sequence), 208 students from summer 1984 to summer 1987 were polled on the truth or falsity of the following 15 statements. Only two of these students stated they had previous exposure to truthfunctional logic.

$N=208$

\section{True/ False Quiz}

99\% T 1. Richmond is the capital of Virginia.

95\% T 2. If you're in Richmond, you're in the capital of Viriginia.

$91 \% \mathrm{~F} 3$. If you put salt in lemonade, you'll make the drink sweeter.

$82 \%$ F 4. Nebraska is east of Ohio.

$93 \% \mathrm{~T} 5$. If you touch the tip of the sparkplug while the mower is on, you'll get a shock.

$66 \%$ F 6. If Dubuque is a city in lowa, then hydrogen peroxide is a good disinfectant for minor cuts and scratches.

$85 \% \mathrm{~T} 7$. If you seldom or never draw good cards, you can't win consistently at poker.

$98 \% \mathrm{~F}$ 8. It's safe to stroll about during a tornado.

$84 \% \mathrm{~F} 9$. If ingesting arsenic is good for your health, then the blue-jay is a songbird.

$73 \% \mathrm{~T} 10$. If you turn the key, the door unlocks.
$99 \%$ T 11. Oranges are a good source of vitamin C.

$64 \% \mathrm{~T} 12$. If the car engine lasts, the oil has been changed regularly.

$83 \% \mathrm{~F} 13$. If dandelions are purple, Jupiter is the largest planet in the solar system.

94\% T14. If you're in Nigeria, you're in Africa.

$88 \% \mathrm{~F} 15$. If the price of gold rises in troubled times, more rain falls in the Mojave desert than in Puget sound.

Aside from learning that Virginians know more about poker than the Midwest, we find that statements 6,9 , and 13 separate the relevance interpretation of 'if...thens...' I am advancing from that of material implication.

6. Antecedent true and consequent true but irrelevant; material implication has this true, but $66 \%$ of the students found it false.

9. Antecedent false and consequent false and irrelevant; material implication has it true, but $84 \%$ of the students opted for false.

13. Antecedent false and consequent true and irrelevant; material implication has it true, but $83 \%$ of the students say it's false. 
It has been objected that given the choice students would have called these statements nonsense rather than false, thus preserving material implication as an interpretation of naturallanguage 'if...thens...'

To this I reply:

1) If by 'nonsense' is meant 'neither factual nor analytic' of the positivists and early analysts, this program now seems to me dead.

2) If by 'nonsense' is meant 'pointless,' doubtless many restless undergraduates find the whole exercise pointless and probably much else in their formal education. Does this prove something of interest? If so, what?

Professor John Hoaglund, Christopher Newport College, Department of Philosophy, 50 Shoe Lane, Newport News, VA 23606 